\title{
PERFIL ESPACIAL E TEMPORAL DE POLUENTES NAS ÁGUAS DA REPRESA MUNICIPAL DE SÃO JOSÉ DO
} RIO PRETO, SÃO PAULO, BRASIL

\author{
Camila de Almeida Melo, Altair B. Moreira* e Márcia Cristina Bisinoti \\ Departamento de Química e Ciências Ambientais, Instituto de Biociências, Letras e Ciências Exatas, Universidade Estadual Paulista \\ “Júlio de Mesquita Filho", Rua Cristóvão Colombo, 2265, 15054-000 São José do Rio Preto - SP, Brasil
}

Recebido em 10/6/08; aceito em 9/2/09; publicado na web em 3/7/09

\begin{abstract}
SEASONAL AND SPATIAL TREND OF POLLUTANTS IN THE WATERS OF THE SÃO JOSÉ DO RIO PRETO MUNICIPAL DAM, SÃO PAULO STATE, BRAZIL. In this manuscript, seasonal and spatial trends of water collected from two sampling places in the Preto River in the Turvo-Grande watershed were evaluated. Water samples were collected during June/07 to July/08 and parameters sulphate, total organic carbon, ammonia, conductivity, dissolved oxygen, temperature, dissolved total solids and nitrate were quantified. Seasonal trend indicated sanitary effluents as a point source of contamination in both sampling points. Vertical trends demonstrated that the Municipal Dam was not stratified and received a diffuse source of pollutants from flooding and agriculture runoffs. It was also verified that there is relatively fast ammonia consumption kinetics having a half-life time of $1.43 \mathrm{~h}$ which can explain the low ammonia concentrations found in these aquatic bodies.
\end{abstract}

Keywords: Preto river; seasonal and spatial trends; pollutants.

\section{INTRODUÇÃO}

A poluição ambiental de corpos aquáticos de uma determinada região reflete o tipo de uso e ocupação do solo. A qualidade e a conservação dos mananciais tem se tornado primordial para o desenvolvimento econômico e social de um país, mais até do que da quantidade de água disponível. O simples monitoramento ambiental é importante e traz informação sobre a qualidade das águas no tocante à legislação vigente (Resolução Conama 357) e enquadramento do recurso hídrico em questão. ${ }^{1}$ Porém, medidas para prevenção e controle da poluição são dependentes do conhecimento do comportamento dos poluentes nos corpos aquáticos. ${ }^{2,3}$

A dinâmica dos poluentes é dependente das variações espaçotemporal. ${ }^{1,4-7}$ Segundo Ahipapthy e Puttaiah, ${ }^{1}$ avaliar as características físico-químicas de corpos aquáticos ajuda a compreender as mudanças observadas ao longo do percurso do rio devido, principalmente, às descargas de efluentes industriais e domésticos e, consequentemente, a capacidade de autodepuração e transformação do corpo aquático. Comportamentos distintos têm sido observados por diversos autores em função do tipo de solo, clima e características físico-químicas dos recursos hídricos. ${ }^{8,9}$ Isto se deve não somente às características já apresentadas, mas também a outros fatores como disponibilidade de luz, temperatura e micro-organismos que afetam as reações fotoquímicas e biológicas no ambiente., ${ }^{4,10-14}$

Vale ressaltar a importância da distinção e identificação de fontes pontuais e difusas num cenário de degradação ambiental, as quais fornecerão informações necessárias para ações de gerenciamento ambiental e políticas públicas no tocante à preservação e manutenção da qualidade do manancial em questão. As fontes pontuais são mais previsíveis e, uma vez identificadas em um monitoramento ambiental, são mais fáceis de serem gerenciadas, como é o caso do lançamento de efluentes industriais e domésticos. As fontes difusas são de difícil identificação e podem ser percebidas usualmente nos períodos chuvosos, sendo que os poluentes alcançam o corpo aquático por meio da deposição atmosférica total e do escoamento superficial agrícola e urbano. Alguns autores têm relatado a importância da identifica-

*e-mail: altair@ibilce.unesp.br ção de fontes difusas no gerenciamento de bacias hidrográficas e alertado para a importância do emprego de perfis espaço-temporais para auxiliar nesta tarefa e, consequentemente, na distinção do uso e ocupação do solo. ${ }^{8,9,13,15}$

O Rio Preto percorre várias cidades, dentre elas São José do Rio Preto (SJRP) que consta com 402.770 habitantes e possui importância econômica para a região. ${ }^{16}$ A Represa Municipal, represamento do Rio Preto, é considerada o cartão postal da cidade e é responsável por $40 \%$ do abastecimento público, exercendo ainda a função de ambiente paisagístico e de lazer. É importante ressaltar que a represa municipal está próxima à Rodovia Federal BR-153 e a Washington Luís, as quais por várias vezes foram responsáveis por aporte acidental de diversos compostos químicos, incluindo amônia.

Estudos que abordem o comportamento espaço-temporal de parâmetros físico-químicos nas águas da represa municipal de São José do Rio Preto são praticamente inexistentes. Desta maneira, considerando a relevância de estudos desta natureza e a importância da área em questão, este trabalho teve como principal objetivo avaliar o comportamento temporal e espacial de parâmetros físico-químicos nas águas do corpo aquático em questão, associando-os com a identificação de fontes pontuais e difusas.

\section{PARTE EXPERIMENTAL}

\section{Área de estudo}

O local de estudo foi a Represa Municipal da cidade de São José do Rio Preto, estado de São Paulo, Brasil (Figura 1S, material suplementar), ao longo do Rio Preto. A represa municipal é constituída de três reservatórios, com área de $650 \mathrm{mil} \mathrm{m}^{2}$, capacidade de armazenamento de 2,27 bilhões de L de água e profundidade de 3,5 m quando da construção em $1955 .^{17}$

O Rio Preto está inserido na Unidade de Gerenciamento de Recursos Hídricos de Número 15, denominada Bacia do Turvo/Grande. É importante destacar que a cidade de São José do Rio Preto não apresenta estação de tratamento de efluentes (ETE) em funcionamento, sendo os corpos aquáticos o destino direto dos esgotos produzidos pela cidade, além do lançamento de efluentes industriais clandesti- 
nos. As principais atividades industriais são basicamente indústrias metalúrgicas (de joalheria, ourivesaria, fundições e de esquadrias metálicas em sua maioria), alimentícias, usinas de açúcar e álcool e movelaria (de todos os tipos: madeira e metal). ${ }^{17,18}$ Entretanto, a região em estudo localiza-se a montante de tais atividades e esta recebe somente os efluentes domésticos da cidade de Cedral - SP (7.607 habitantes, segundo censo de IBGE/2007), de Engenheiro Schmidt (Distrito de São José do Rio Preto com 5.000 habitantes aproximadamente) e alguns lançamentos clandestinos da cidade de São José do Rio Preto, uma vez que o efluente produzido na cidade é lançado posterior aos locais monitorados. Ademais, na área de estudo as atividades são basicamente agropecuárias (cana-de-açúcar, laranja e criação de gado de corte e de leite).

\section{Pontos de amostragem}

Para a realização do trabalho foram selecionados 2 locais de amostragem, localizados ao longo das represas do Rio Preto. Um dos pontos de coleta foi denominado Captação do Rio Preto (CAPRP), localizado em S2048'29.2" e W049²2'24.1" e o outro, de Passarela do Rio Preto (PRP), localizado a S20 48'30.5' e W049²2'02.4”, como ilustrado na Figura $1 \mathrm{~S}$ por pontos 1 e 2, respectivamente.

As amostragens de água foram realizadas durante um ano hidrológico, no período de Julho/2007 a Julho/2008, totalizando 18 coletas de água da represa, sendo 4 para perfil temporal 24 h, 2 para perfil de profundidade e o restante para o perfil temporal mensal.

\section{Amostragem}

As amostras de águas naturais foram coletadas, em triplicata, diretamente em frascos de polietileno e vidro, previamente limpos em laboratório (sala limpa, classe 100) e ambientados com a própria amostra, após a realização de no mínimo três enxágues em campo. As amostras destinadas à quantificação de amônia $\left(\mathrm{NH}_{3}\right)$, nitrito $\left(\mathrm{NO}_{2}^{-}\right)$, nitrato $\left(\mathrm{NO}_{3}^{-}\right)$, alcalinidade e sulfato $\left(\mathrm{SO}_{4}{ }^{-2}\right)$ foram coletadas em garrafas PET (polietileno tereftalato) de $510 \mathrm{~mL}$, as quais foram acondicionadas em caixa térmica contendo gelo e, em seguida, transportadas para o laboratório sob refrigeração. As amostras para quantificação de carbono orgânico total (COT) e fósforo foram coletadas em frascos de vidro âmbar de $30 \mathrm{~mL}$, previamente lavados, acondicionados da mesma maneira que para os parâmetros citados acima. A quantificação de alcalinidade, amônia e COT foram feitas no mesmo dia da coleta e as demais foram feitas conforme o prazo de validade de cada parâmetro, seguindo-se as recomendações da Norma Brasileira NBR 9898. ${ }^{19}$ As amostras para quantificação dos parâmetros amônia, Nitrato, COT e fósforo foram preservadas com $\mathrm{H}_{2} \mathrm{SO}_{4}$ concentrado até $\mathrm{pH}<2$.

\section{Parâmetros analisados}

Em todas as amostras coletadas os parâmetros físico-químicos temperatura (T), pH, condutividade (CD), sólidos totais dissolvidos (STD) e oxigênio dissolvido (OD) foram quantificados, em triplicata, diretamente no local de amostragem (em campo) por emprego de equipamentos multiparâmetros previamente calibrados (marca Hanna, modelos HI991300 e HI9146-04). Para fins de comparação e validação estes parâmetros foram quantificados também no laboratório empregando-se equipamentos de bancada, seguindo recomendações de métodos oficiais, ${ }^{20}$ bem como medindo-se em campo soluções padrão como amostra desconhecida.

Amônia foi determinada espectrofotometricamente, fundamentada pela reação do salicilato de sódio catalisada pelo nitroprussiato de sódio (Método 4500- $\mathrm{NH}_{3} \mathrm{E}$ ) ${ }^{20}$ com quantificação em $640 \mathrm{~nm}$.
Nitrito foi determinado por método espectrofotométrico, fundamentado na reação com sulfanilamina e n(1-naftil) etilenodiamina, (Método $\left.4500-\mathrm{NO}_{2} \mathrm{~B}\right),{ }^{20}$ com quantificação em $420 \mathrm{~nm}$. O nitrato foi quantificado por método espectrofotométrico (Método $4500 \mathrm{NO}_{3} \mathrm{~B}$ ). ${ }^{20}$

O fósforo total foi quantificado pelo método espectrofotométrico, fundamentado na decomposição ácida da amostra e posterior tratamento com ácido ascórbico, com quantificação em $880 \mathrm{~nm}$ (Método 4500-P E). ${ }^{20}$

Sulfato foi quantificado pelo método turbidimétrico por reação com cloreto de bário em meio tamponado (Método 4500$\left.\mathrm{SO}_{4}{ }^{2-} \mathrm{E}\right){ }^{20}$

Carbono orgânico total foi quantificado com o auxílio de um analisador de carbono Orgânico total da Shimadzu, modelo TOC VCSN, previamente calibrado.

Alcalinidade foi quantificada por método titulométrico na presença de alaranjado de metila como indicador e ácido sulfúrico 0,04 mol L ${ }^{-1}$ como titulante (Método 2320B). ${ }^{20}$

Os dados de precipitação acumulada mensal foram adquiridos junto à Secretaria de Agricultura e Abastecimento do Estado de São Paulo e Instituto Agronômico. ${ }^{21}$

\section{Perfis verticais e temporais}

Os perfis verticais e temporais ( $24 \mathrm{~h}$ e mensal) foram obtidos para os dois locais de amostragem. Para o perfil vertical as amostras foram coletadas na superfície $(0,3 \mathrm{~m})$ e nas profundidades máximas encontradas de 1,5 e $0,5 \mathrm{~m}$ para PRP e CAPRP, respectivamente. Foram feitas coletas para perfis verticais nos dois locais de estudo Passarela do Rio Preto e Captação do Rio Preto utilizando um coletor de profundidade.

\section{Experimentos de cinética de consumo de amônia}

Nove garrafas PET de 2,0 L foram cortadas na parte superior e lavadas com água destilada. Em três delas foram adicionados $1,0 \mathrm{~L}$ de água destilada, sendo que nas outras garrafas, em triplicata, foram adicionadas amostras dos dois locais de amostragem, seguidos da adição de solução estoque de amônia para uma concentração final de $10,0 \mathrm{mg} \mathrm{L}^{-1}$. Os microcosmos foram protegidos com uma tela para impedir a entrada de insetos nos frascos. A temperatura foi mantida controlada entre 24 e $25^{\circ} \mathrm{C}$, além da luz do laboratório ter permanecido acesa durante todo o período do experimento. $\mathrm{O}$ monitoramento da cinética de consumo de amônia começou a ser feito desde o tempo zero, ou seja, a partir do momento em que foi adicionada a solução estoque de amônia, variando o tempo de retirada de alíquotas para a quantificação de amônia em função do tempo de consumo da mesma.

\section{Análise dos dados}

As análises de componentes principais (PCA) foram realizadas empregando o programa PAST versão 1.85.22 Para a análise estatística e montagem de matrizes de dados utilizou-se o programa Excell e Origin 6.1. Antes de processados, os dados foram autoescalados por métodos convencionais.

\section{RESULTADOS E DISCUSSÃO}

\section{Perfil temporal mensal}

A Figura 1a apresenta os valores mínimos e máximos obtidos para os parâmetros físico-químicos monitorados, no período de Julho/07 a Julho/08, para os pontos PRP e CAPRP. 

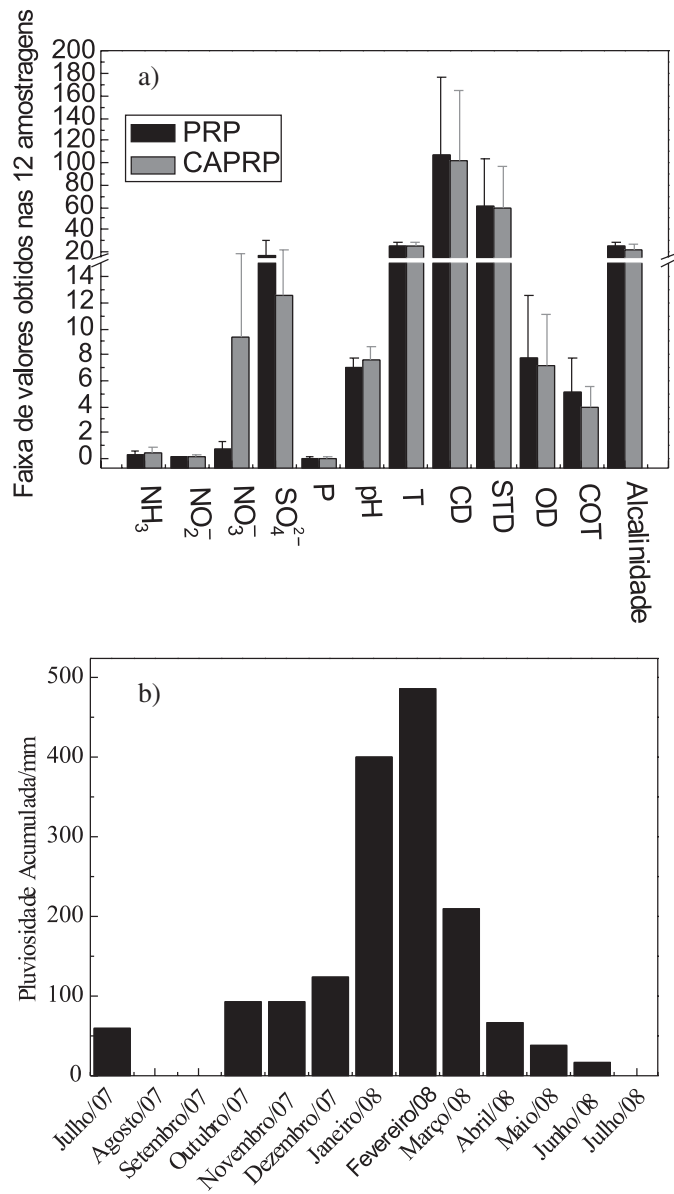

Figura 1. a. Gráfico box-plot dos valores mínimos e máximos (perfil mensal) dos parâmetros físico-químicos quantificados em laboratório e in situ encontrados para os pontos PRP e CAPRP nas águas da Represa Municipal de São José do Rio Preto/SP, para o período de Julho/2007 a Julho/2008; os parâmetros amônia, nitrito, nitrato, sulfato, fósforo, alcalinidade, TOC, STD e OD estão em $\mathrm{mg} \mathrm{L}^{-1}$, condutividade em $\mu S \mathrm{~cm}^{-1}$ e Temperatura em ${ }^{\circ} \mathrm{C}$; b. comportamento pluviométrico, em mm, obtido para a cidade de São José do Rio Preto (Centro Integrado de Informações Agrometereológicas CIIAGRO, 2008)

A Resolução do Conselho Nacional do Meio Ambiente (CONAMA) 357 de 2005 é a legislação vigente no Brasil que estabelece valores máximos permitido para parâmetros físico-químicos em águas superficiais em função da classe, ${ }^{23}$ sendo que, segundo o decreto $10.755 / 77$ do estado de São Paulo, os locais monitorados classificam-se como classe 2. Quanto ao parâmetro OD, a legislação estabelece um valor mínimo de $5,0 \mathrm{mg} \mathrm{L}^{-1}$ para águas superficiais. Em 50\% das amostragens realizadas, valores de OD estiveram abaixo de $5,0 \mathrm{mg} \mathrm{L}^{-1}$ para os dois locais monitorados o que, segundo alguns autores, pode ser atribuído à presença de matéria orgânica biodegradável e à utilização de OD por micro e macro fauna, resultando no consumo de OD e, portanto, em concentrações menores..$^{24,25}$ Os corpos aquáticos monitorados apresentaram condições que possibilitam a presença de vida aquática, porém houve casos em que a concentração de oxigênio dissolvido foi elevada, como é o caso do CAPRP (concentração de OD de $11,1 \mathrm{mg} \mathrm{L}^{-1}$ para Julho/07, por exemplo), que recebe efluentes domésticos clandestinamente a montante do local de coleta e, jusante do PRP. Concentrações de OD acima da saturação podem ser indicativas de início de processo de eutrofização, fenômeno no qual o processo de fotossíntese realizado pelas algas contribui para a elevação das concentrações de OD na água, bem como a ocorrência de temperaturas da água ao redor de $21^{\circ} \mathrm{C}$ no período do inverno. ${ }^{1,26}$
Os parâmetros físico-químicos carbono orgânico total, sólidos totais dissolvidos e condutividade apresentaram maiores concentrações nos meses de Dezembro/07 e Fevereiro e Março/08, que foram os meses com maior pluviosidade acumulada (Figura 1b) evidenciando, assim, a presença de fontes difusas pelo escoamento superficial mesmo com o aumento da diluição. ${ }^{27} \mathrm{O}$ aumento da condutividade elétrica nestes locais de amostragem em função do aumento da pluviosidade pode ser atribuído ao aumento do transporte de sais através do escoamento superficial das águas das áreas urbanas e rural para o corpo receptor. Cabe ressaltar que o ponto PRP apresentou maiores valores para os parâmetros citados acima, quando comparados ao ponto CAPRP. Em contrapartida, o parâmetro pH mostrou-se ligeiramente maior no CAPRP que no PRP.

Os parâmetros amônia, nitrito, sulfato, sólidos totais dissolvidos e pH apresentaram-se de acordo com os valores legislados pela Resolução CONAMA 357/2005 para rios de classe 2 nos dois locais de amostragem. As concentrações de nitrato (Figura 1a) excederam o valor máximo permitido pela Resolução CONAMA 357/2005 no mês de Junho de 2008 para o CAPRP.

Já para o parâmetro fósforo total a legislação preconiza valores de até $0,030 \mathrm{mg} \mathrm{L}^{-1}$ para ambientes lênticos e até $0,050 \mathrm{mg} \mathrm{L}^{-1}$ para ambientes intermediários. No período de Julho/07 a Agosto/07, a concentração de fósforo total superou os valores esperados em ambientes lênticos, sendo o restante do período monitorado de acordo com valores legislados para ambientes represados, para ambos os locais de amostragem. Bowes et al..$^{27}$ relacionam as concentrações de fósforo total com o fluxo do corpo aquático, atribuindo o aumento nas concentrações deste parâmetro com o fluxo à presença de fontes difusas de poluição, sendo que a redução das concentrações de fósforo com o aumento do fluxo indica a predominância de fontes pontuais, como lançamento de esgoto doméstico e efluentes industriais. Neste contexto, neste trabalho a presença de fósforo pode ser atribuída às fontes pontuais.

$\mathrm{O}$ local de amostragem CAPRP apresentou-se visivelmente eutrofizado nos períodos de menor pluviosidade. Este é um problema que precisa ser atendido pelas autoridades municipais, uma vez que tal processo pode afetar o tratamento da água. A prefeitura de São José do Rio Preto está finalizando a construção de uma Estação de Tratamento de Efluentes que deverá tratar $100 \%$ do efluente gerado na cidade. Porém, este problema deverá continuar, uma vez que os aportes de efluentes domésticos observados no CAPRP e PRP não são proveniente da cidade de SJRP e sim, dos municípios localizados a montante dos locais de amostragem.

O comportamento dos poluentes nestes corpos aquáticos permite inferir que a maioria das fontes são difusas, uma vez que a concentração de muitos parâmetros aumenta mesmo no período de maior pluviosidade, o que pode ser relacionado à deposição úmida e ao escoamento superficial agrícola, bem como à drenagem de águas pluviais. Vale ressaltar que a região tem passado por um processo de crescimento acelerado da atividade canavieira, a qual no estado de São Paulo é acompanhada pelas queimadas que contribuem com as emissões de COx e NOx para o ar, que poderão contribuir para a poluição dos corpos aquáticos.

Segundo levantamento realizado por Graciano et al. ${ }^{28}$ a estimativa de emissão de poluentes atmosféricos, calculada de acordo com a $\mathrm{EPA},{ }^{29}$ incluindo apenas a emissão veicular na cidade de SJRP para o período de Julho/07 a Julho/08 foi de 47.764 t de monóxido de carbono, $12.443 \mathrm{t}$ de hidrocarbonetos, $8.345 \mathrm{t}$ de óxidos de nitrogênio, $882 \mathrm{t}$ de óxidos de enxofre e $725 \mathrm{t}$ de material particulado. As quantidades elevadas de emissão atmosférica de fontes móveis na região referem-se principalmente à emissão veicular proveniente de duas grandes rodovias (rodovias Washington Luís e Transbrasiliana, $\mathrm{Br}-153$ ) que cruzam a cidade, e não à frota veicular local, mas podem contribuir significativamente como incremento de fonte difusa. 
A interpretação da correlação entre os parâmetros monitorados e a sazonalidade de maneira univariada é bastante difícil, como evidenciado na discussão anterior. Nestes casos a quimiometria oferece um conjunto de ferramentas multivariadas, que possibilitam diminuir a dimensionalidade da matriz de dados, permitindo uma melhor visualização e interpretação dos resultados obtidos. Dentre estas, a análise de componentes principais (PCA) se destaca, pois pode resumir em poucas e importantes dimensões a maior parte da variabilidade de uma matriz de dados de um grande número de variáveis, sendo que a variância explicada por estes poucos eixos principais independentes pode ser conhecida.

A identificação dos locais de amostragem na Figura 2 é feita de maneira que as letras representam as siglas dos locais de amostragem (PRP e CAPRP), ao lado direito da letra os números de 01 a 12 , que indicam o mês de coleta, e o último número (07 ou 08) o ano da coleta. Os eixos x e y dos gráficos representam as componentes principais $(\mathrm{CP})$. Em cada eixo a direção positiva e negativa representa os parâmetros físico-químicos que discriminam amostras naquela direção. Ao analisar um gráfico de PCA podem-se identificar quais parâmetros separam cada local de amostragem.

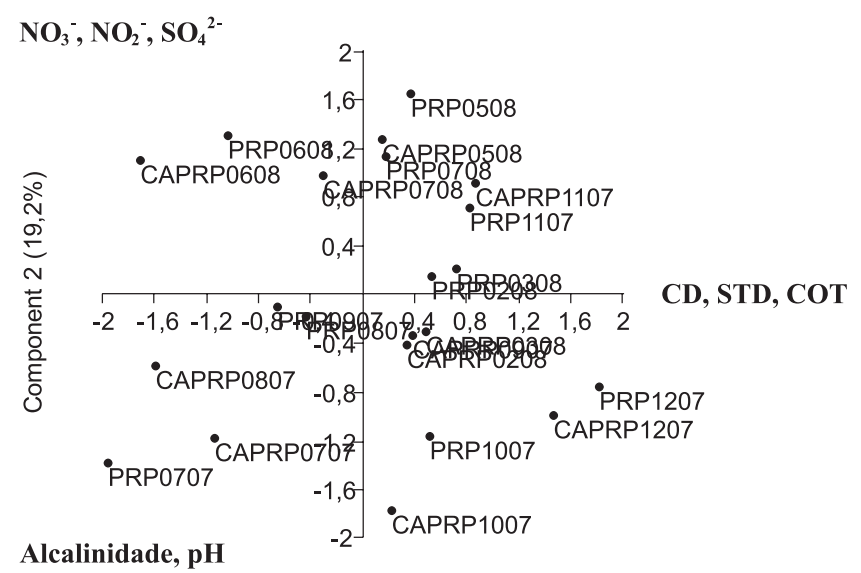

Component $1(31,3 \%)$

Figura 2. Componentes principais 1 e 2 dos locais de amostragem CAPRP e PRP para a análise de parâmetros físico-químicos durante 12 coletas realizadas no período de Julho/07 a Julho/2008

A Figura 2 ilustra a configuração em duas dimensões, das componentes principais 1 e 2, que juntas explicam $50,5 \%$ da variância dos dados, dos pontos referentes às amostras. Os quadros nos eixos das componentes principais explicam a influência de determinados parâmetros monitorados sobre os locais de amostragem. As espécies oxidadas sulfato, nitrito e nitrato (nitrificação da uréia), oriundas do lançamento de efluentes urbanos sem tratamento, bem como em menor extensão de fertilizantes agrícolas, têm influência sobre as amostras PRP e CAPRP, para os meses de coleta Novembro/07 e Maio, Junho e Julho de 2008. De acordo com a Figura 1b, estes meses refletem as menores precipitações acumuladas $(<50 \mathrm{~mm})$ evidenciando que tais espécies devem ser provenientes principalmente de efluentes domésticos.

Nos meses de Julho e Agosto de 2007 (Figura 2), período de baixa precipitação pluviométrica, as amostras de ambos locais de amostragem foram discriminadas pelos parâmetros $\mathrm{pH}$ e alcalinidade. A variância em função da alcalinidade pode ser atribuída ao fenômeno de eutrofização (produtividade primária das algas), sendo que as transformações de nitrogênio através da assimilação pelas algas na coluna d'água e a desnitrificação na superfície do sedimento podem levar ao consumo de $\mathrm{H}^{+}$e, consequentemente, alteração no valor de $\mathrm{pH}$. Sendo que para os meses mais chuvosos os locais de amostra- gem foram discriminados pelos parâmetros condutividade, sólidos totais dissolvidos e carbono orgânico total, que indicam influência de espécies lixiviadas do solo, bem como de efluentes domésticos e águas de escoamento superficial. ${ }^{30} \mathrm{O}$ aumento da concentração de tais parâmetros no período chuvoso pode estar associado a outras fontes, como a deposição atmosférica total.

\section{Perfil temporal $24 \mathrm{~h}$}

A Figura 3(a e b) mostra o perfil temporal 24 h dos parâmetros analisados para o mês de Agosto/07 do ponto PRP. Os valores de $\mathrm{pH}$ e temperatura não apresentaram variações significativas, demonstrando que o local de estudo não sofre alterações quanto ao aporte de efluentes ácidos ou básicos. Já o parâmetro OD variou significativamente, sendo que a menor concentração foi observada às $6 \mathrm{~h}$ da manhã. Este comportamento chama a atenção considerando que este horário coincide com o menor valor de T e, portanto, é esperada maior concentração de OD. Oliveira ${ }^{13}$ ao estudar alguns aspectos limnológicos nas águas da Lagoa do Batoque/Ceará/Brasil observou comportamento semelhante para OD, ou seja, menor concentração às $6 \mathrm{~h}$ e um aumento às $12 \mathrm{e} 16 \mathrm{~h}$, atribuindo tal comportamento à atividade fotossintética.

As concentrações de amônia e nitrato apresentaram comportamentos inversos, onde os picos de maiores concentrações de nitrato $(9 \mathrm{~h}$ da manhã do dia 15/08 e 12 e 18 h do dia 16/08) coincidiram com os de menores concentrações de amônia, indicando que a mesma deve ter uma cinética de consumo relativamente rápida nestas águas. As maiores concentrações de amônia foram observadas às $6 \mathrm{~h}$ da manhã do dia 16/08 (Figura 3a).

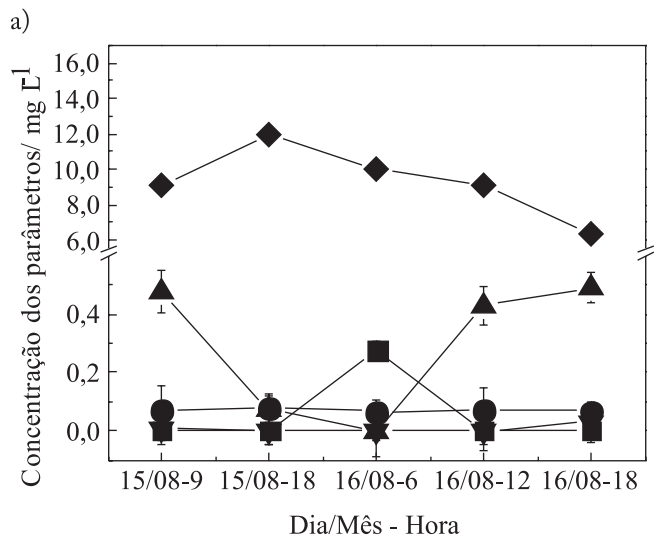

b)

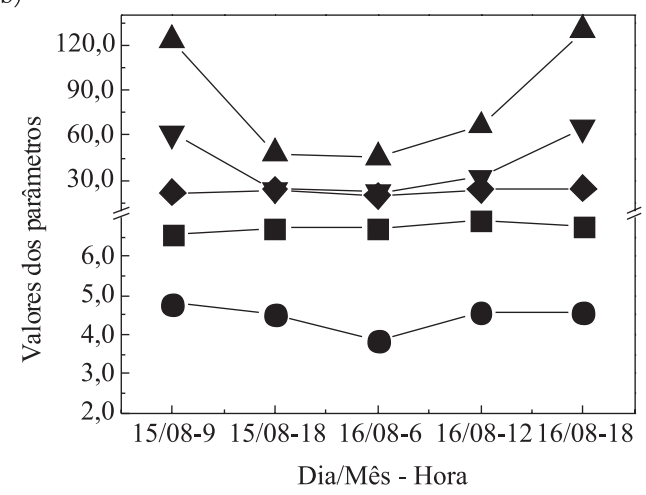

Figura 3. Comportamento temporal 24 h dos parâmetros: (a) amônia - $\mathbf{\square}$-, nitrito - -, nitrato - $\mathbf{\Delta}$-, sulfato - - e fósforo - $\mathbf{\nabla}$ - (valores em $\left.\mathrm{mg} \mathrm{L}^{-1}\right)$ e (b) $O D$ - - e STD - $\mathbf{\nabla}$ - (valores em $\left.m g L^{-1}\right)$, condutividade - $\mathbf{\Delta}-\left(\mu S \mathrm{~cm}^{-1}\right), T$ - $\left({ }^{\circ} \mathrm{C}\right)$ e pH - - em amostras de águas coletadas nos dias 15 e 16/08 no ponto Passarela do Rio Preto (PRP) 
O experimento de cinética de consumo da amônia nestas águas é de segunda ordem com uma constante de decaimento de $0,070 \mathrm{~h}^{-1}$, sendo o tempo de meia vida da amônia foi de 1,43 h nestas águas. Vale ressaltar que não houve cinética de consumo de amônia na água deionizada. Desta maneira, a cinética de consumo de amônia observada para estes corpos aquáticos pode ser atribuída à presença de bactérias nitrificantes, presentes no mesmo, juntamente ao lançamento de efluente doméstico que, consequentemente, facilitam a nitrificação das espécies de N. Este resultado auxilia o entendimento do comportamento observado no item perfil temporal mensal, onde era esperado que as concentrações de amônia fossem superiores às de nitrato em função do lançamento de efluentes domésticos. Com o tempo de meia vida da amônia nestas águas de poucas horas, associado às condições de aeração, espera-se a oxidação das formas mais reduzidas do nitrogênio à nitrato, explicando os resultados obtidos.

a)

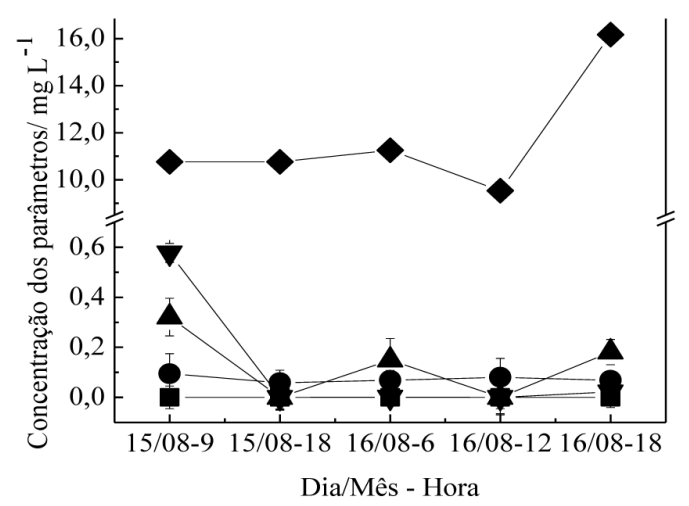

b)

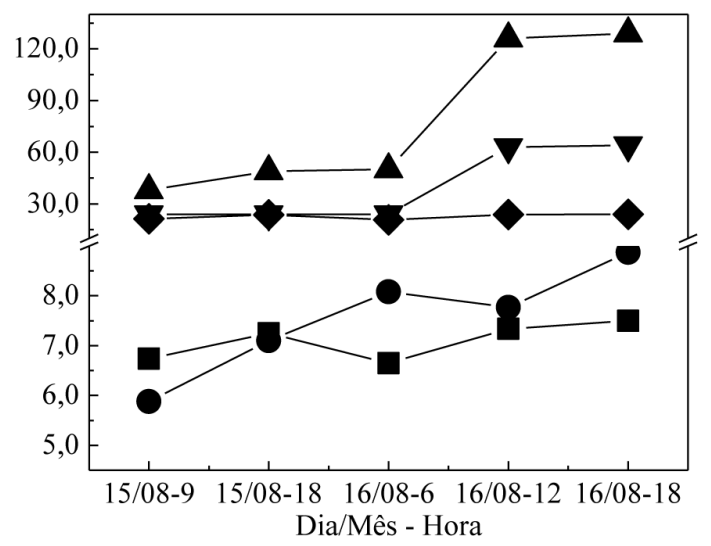

Figura 4. Comportamento temporal 24 h dos parâmetros (a) amônia - -, nitrito - -, nitrato - $\mathbf{-}$-, sulfato - - e fósforo - $\mathbf{\nabla}$ - (valores em $\left.\mathrm{mg} \mathrm{L}^{-1}\right)$ e (b) $S T D$ - $\mathbf{\nabla}$ - $e$ OD ๑- (valores em $\left.m g L^{-1}\right)$, condutividade - $\mathbf{\Delta}-\left(\mu S \mathrm{~cm}^{-1}\right), T$ - $\left({ }^{\circ} \mathrm{C}\right)$ e $\mathrm{pH}-\mathbf{-}-$ em amostras de águas coletadas nos dias 15 e 16/08 no ponto Captação do Rio Preto (CAPRP)

O perfil observado no CAPRP (Figura 4) foi diferente para alguns parâmetros como pH e OD quando comparado ao local de amostragem PRP. É importante destacar que ambos são distantes apenas $1 \mathrm{~km}$, porém o CAPRP está a jusante do PRP e recebe maior carga de efluentes. Houve uma variação nos valores de $\mathrm{pH}$ durante o perfil, principalmente no dia 16/08 às $6 \mathrm{~h}$, o que pode indicar que neste local pode ter havido algum lançamento de efluente. Os valores de OD para CAPRP são maiores que os valores encontrados para PRP nos perfis, indicando que neste intervalo de espaço pode existir uma fonte de oxigênio a mais que contribua para este aumento, bem como micro-organismos fotossintéticos. Como citado anteriormente, alguns autores explicam que esse aumento de OD está associado à alta densidade de produtores primários (macrófitas). ${ }^{31,32}$ Esteves e colaboradores ${ }^{31}$ investigaram as variações nictemerais de alguns fatores limnológicos, durante o período de Dezembro/1985 a Outubro/1986, no mesmo local de estudo deste trabalho (Represa Municipal de SJRP) e encontraram a presença de algumas macrófitas, Eichhornia azurea e Tupha dominguensis que podem existir até os dias atuais.

No mês de Outubro/07 (resultados não apresentados) também foi traçado este tipo de perfil temporal para ambos os pontos de coleta. Porém, diferentemente dos perfis apresentados nas Figuras 3 e 4, estes não apresentaram variações significativas para os parâmetros analisados. Nota-se que há uma constância de todos os parâmetros e, portanto, conclui-se que neste período a represa não recebeu lançamentos que lhe causassem impactos significativos com relação aos parâmetros avaliados.

\section{Perfil vertical}

A represa municipal de SJRP foi construída inicialmente com uma profundidade máxima de $3,5 \mathrm{~m}$ e a partir das amostragens realizadas observou-se que, atualmente, as profundidades são de 1,5 m para o PRP e de 0,5 m para CAPRP. Já a partir desses dados pode-se concluir que a represa apresenta um nível de assoreamento considerável, sendo que precisam ser tomadas medidas que minimizem este problema. Esteves et al..$^{31}$ encontraram uma profundidade máxima de 2,5 m para o ponto CAPRP nos anos de 1985 e 1986. Os perfis de profundidades traçados para ambos os pontos de coleta não apresentaram variações significativas para os parâmetros físicoquímicos avaliados. A Figura $2 \mathrm{~S}$ (material suplementar) ilustra o perfil obtido para o ponto PRP. Somente para os parâmetros condutividade e sólidos totais dissolvidos houve um aumento com o aumento da profundidade, que deve estar associado a um possível revolvimento de material de fundo. Em contrapartida, Mariani ${ }^{33}$ ao realizar caracterização limnológica no reservatório Rio Grande observou que o parâmetro condutividade diminuiu em profundidades maiores. Estudos de perfis verticais que demonstram estratificações térmicas e químicas são comumente encontrados para ambientes com águas profundas..$^{24,34,35}$ Desta maneira, pode-se concluir que as águas da represa municipal de SJRP não se encontravam estratificadas quimicamente nos dias de coletas, ou seja, apresentavam boas condições de dispersão de poluentes.

\section{CONCLUSÕES}

Neste trabalho pode-se concluir que para os meses estudados (Junho/07 a Julho/08) ocorreu um aumento na concentração de parâmetros como sulfato, COT, amônia, condutividade e STD (período seco ao chuvoso) tanto para o PRP quanto para o CAPRP. O perfil temporal $24 \mathrm{~h}$ indica que há fontes pontuais de contaminação por efluentes domésticos, sendo que no perfil temporal sazonal se verificou a presença de fontes difusas devido ao escoamento superficial agrícola e urbano, bem como a deposição total atmosférica. De acordo com o perfil vertical a represa não se apresenta estratificada termicamente e, portanto, há uma boa dispersão de poluentes na mesma. Estes resultados trazem um panorama da real situação das águas da represa municipal que serve a cidade de diversas formas, permitindo concluir que a sazonalidade tem um papel fundamental na tomada de decisões nos aspectos de gerenciamento dos recursos em questão. Conclui-se ainda que as fontes difusas contribuem significativamente para a poluição, desta maneira, o simples gerenciamento das fontes pontuais não solucionará os efeitos antrópicos ao qual este corpo aquático está susceptível. 


\section{MATERIAL SUPLEMENTAR}

As Figuras $1 \mathrm{~S}$ e $2 \mathrm{~S}$, referentes ao mapa com identificação dos locais de amostragem e comportamento dos parâmetros em função da profundidade dos locais de amostragem encontram-se disponíveis gratuitamente para consulta em http://quimicanova.sbq.org.br, na forma de arquivo PDF.

\section{AGRADECIMENTOS}

À Fundação de Amparo à Pesquisa do Estado de São Paulo pelo auxílio (05/51242-8) e bolsas (07/50461-3, 08/03246-2) concedidas.

\section{REFERÊNCIAS}

1. Ahipathy, M. V.; Puttaiah, E. T.; Environ. Geol. 2006, 49, 1217.

2. Simões, F. D. S.; Yabe, M. J. D. S.; Moreira, A. B.; Bisinoti, M. C.; Quim. Nova 2007, 30, 1835.

3. Simões, F. D.; Moreira, A. B.; Bisinoti, M. C.; Gimenez, S. M. N.; Yabe, M. J. S.; Ecol. Indic. 2008, 8, 476.

4. Esteves, F. A.; Fundamentos de Limnologia, Ed. Interciência/FINEP: Rio de Janeiro, 1988.

5. Perona, E.; Bonilla, I.; Mateo, P.; Sci. Total Environ. 1999, 241, 75.

6. Marques, M. N.; Cotrim, M. B.; Pires, M. A. F.; Beltrame, O.; Quim. Nova 2007, 30, 1171.

7. Armas, E. D.; Rosim Monteiro, R. T.; Amâncio, A. V.; Lopes Correa, R. M.; Guercio, M. A.; Quim. Nova 2005, 28, 975.

8. Herrera-Silveira, J. A.; González, F. U. T.; Macedo, M. L. A.; Estuar. Coast. Shelf S. 2008, 78, 418.

9. Miller, J. D.; Adamson, J. K.; Hirst, D.; Sci. Total Environ. 2001, 265, 27.

10. Ouyang, Y.; Nkedi-Kizza, P.; Wu, Q. T.; Shinde, D.; Huang, C. H.; Water Res. 2006, 40, 3800

11. do Carmo, M. S.; Boaventura, G. R.; Oliveira, E. C.; Quim. Nova 2005, 28,565 .

12. Barbosa, F. A. R.; Bicudo, C. E. M.; Huszar, V. L. M. Em Limnology in Brazil; Tundisi, J. G.; Bicudo, C. E. M.; Matsumura-Tundisi, T., eds.; ABC/SBL: Rio de Janeiro, 1995.

13. Oliveira, E. C.; Tese de Doutorado, Universidade de São Paulo, Brasil, 2006.

14. Medeiros, P. R.; Barbosa, J. E. L.; Silva, A. M. A.; Crispim, M. C. B.; Rev. Biol. Cien. da Terra 2006, Suplemento Especial, 73.
15. Greiner, R.; Herr, A.; Brodie, J.; Haynes, D.; Mar. Pollut. Bull. 2005, 51,128 .

16. http://www.ibge.gov.br/cidadesat/topwindow.htm?1, acessada em Agosto 2007.

17. http://www.riopreto.sp.gov.br/externos/sm_planejamento/conjuntura_ economica/2007/6.pdf, acessada em Abril 2008.

18. Relatório de Qualidade de Águas Interiores no Estado de São Paulo CETESB - 2005, disponível em http://www.cetesb.sp.gov.br/, acessada em Novembro 2008.

19. ABNT - Associação Brasileira de Normas Técnicas; NBR 9898: preservação e técnicas de amostragem de efluentes líquidos e corpos receptores, Rio de Janeiro, jun. 1987.

20. Clesceri, L. S.; Greenberg, A. E.; Eaton, A. D.; Standard Methods for the Examination of water and waste water, $20^{\text {th }}$ ed., APHA, AWWA, WEF: Washington, 1998.

21. http://www.ciiagro.sp.gov.br, acessada em Novembro 2008.

22. http://folk.uio.no/ohammer/past/, acessada em Outubro 2008.

23. http://www.mma.gov.br/port/conama/res/res05/res35705.pdf, acessada em Novembro 2006.

24. Acharya, B. C.; Das, J.; Water, Air, Soil Pollut. 2003, 150, 163.

25. Ravindra, K.; Meenakshi, A.; Rani, M.; Kaushik, A.; J. Environ. Monitor. 2003, 5, 419 .

26. Taniguchi, G. M.; Tese de Doutorado, Universidade Federal de São Carlos, Brasil, 2002.

27. Bowes, M. J.; Smith, J. T.; Jarvie, H. P.; Neal, C.; Sci. Total Environ. 2008, 395, 125 .

28. Graciano, T.; Bisinoti, M. C.; Moreira, A. B.; Resumos da 30a Reunião Anual da Sociedade Brasileira de Química, Águas de Lindóia, Brasil, 2007.

29. United States. Environmental Protection Agency-EPA; Emission Inventory Improvement Program. Volume II: Introduce to the Stationary Point Souce Emission Inventory Development, falta editora: cidade,1997.

30. Prestes, E. C.; Anjos, V. E.; Sodré, F. F.; Grassi, M. T.; J. Braz. Chem. Soc. 2006, 17, 53 .

31. Esteves, F. A.; Bozelli, R. L.; Camargo, A. F. M.; Roland, F.; Thomas, S. M.; Acta Limn. Bras. 1988, 11, 99.

32. Taniguchi, G. M.; Bicudo, D. C.; Sennab, P. A. C.; Braz. Arch. Biol. Techn. 2004, 47, 961 .

33. Mariani, C. F.; Dissertação de Mestrado, Universidade de São Paulo, Brasil, 2006.

34. Talling, J. F.; Hydrobiologia 2004, 524, 215.

35. Anderson, M. A.; Lawson, R.; Water Res. 2007, 41, 4457. 
PERFIL ESPACIAL E TEMPORAL DE POLUENTES NAS ÁGUAS DA REPRESA MUNICIPAL DE SÃO JOSÉ DO RIO PRETO, SÃO PAULO, BRASIL

Camila de Almeida Melo, Altair B. Moreira* e Márcia Cristina Bisinoti

Departamento de Química e Ciências Ambientais, Instituto de Biociências, Letras e Ciências Exatas, Universidade Estadual Paulista "Júlio de Mesquita Filho", Rua Cristóvão Colombo, 2265, 15054-000 São José do Rio Preto - SP, Brasil
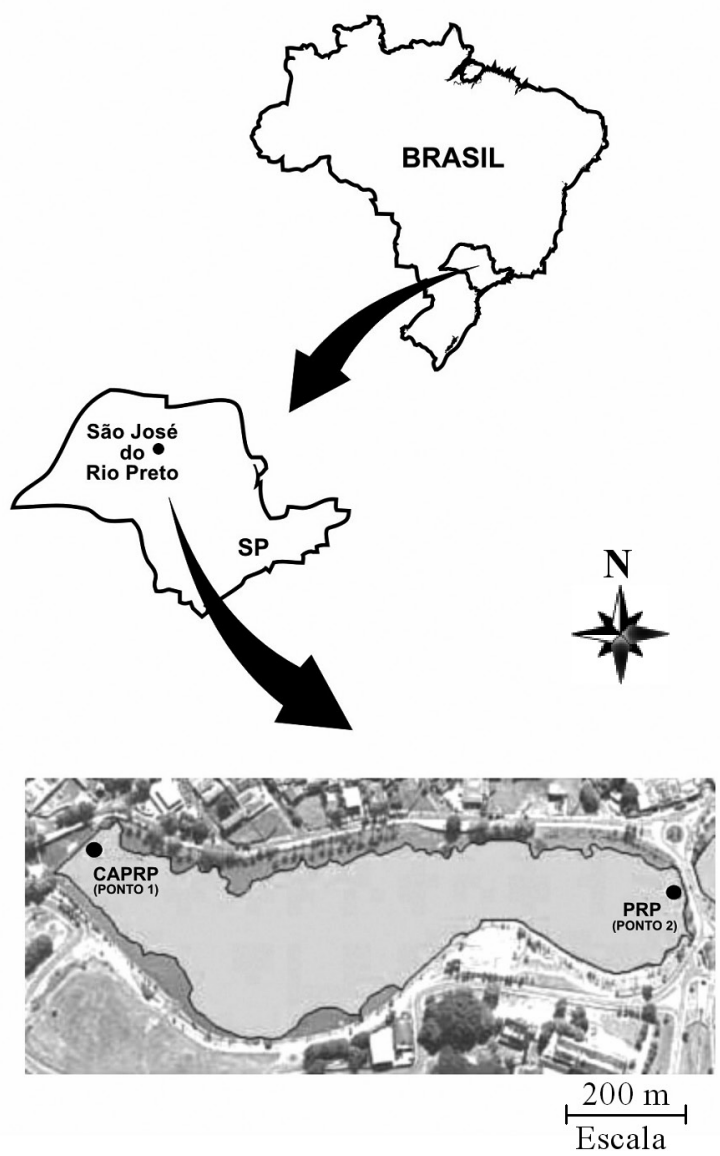

Figura 1S. Localização da Represa Municipal de São José do Rio Preto-SP, estado de São Paulo, Brasil, sendo que o ponto 1 foi denominado Captação do Rio Preto (CAPRP) e o ponto 2, Passarela do Rio Preto (PRP)

*e-mail: altair@ibilce.unesp.br a)

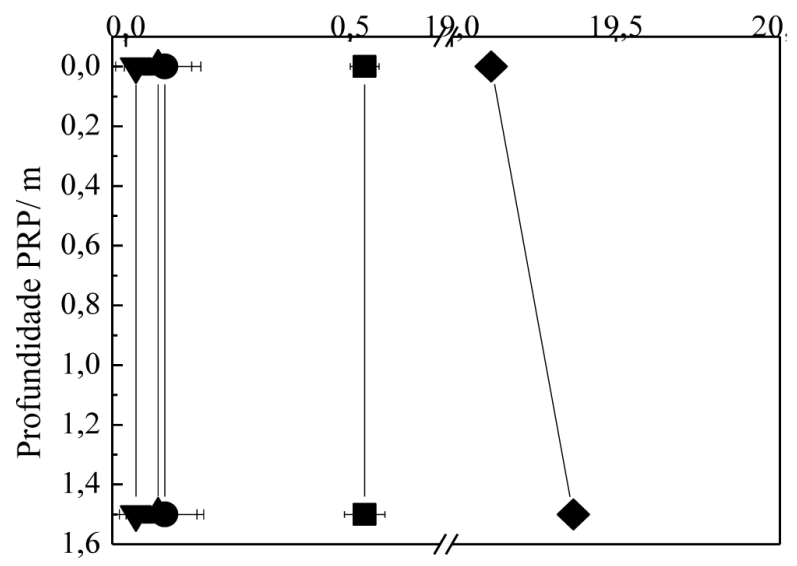

b)

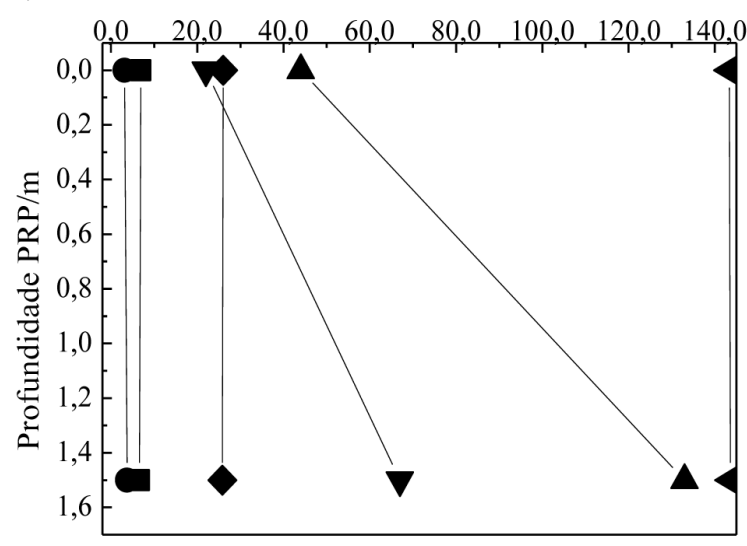

Figura 2S. Comportamento dos parâmetros (a) amônia - $\mathbf{\square}$-, nitrito - •-, nitrato - $\boldsymbol{\Delta}_{-}$, sulfato - $\mathbf{\nabla}$ - e fósforo - - (valores em $\left.m g L^{-1}\right)$ e (b) STD - $\mathbf{\nabla}$-, COT - ४ - e OD - $\mathbf{\Delta}$ - (valores em $\left.\mathrm{mg} \mathrm{L}^{-1}\right)$, condutividade - - $\left(\mu \mathrm{S} \mathrm{cm}^{-1}\right), T-\bullet-\left({ }^{o} \mathrm{C}\right)$ e pH - - em amostras de águas coletadas no dia 15/09 às $11 \mathrm{~h}$ no ponto Passarela do Rio Preto (PRP) 